\title{
A Modified Nature Publishing Index via Shannon Entropy
}

\author{
Yelin Fu, ${ }^{1,2}$ Ming Wang, ${ }^{3}$ and Kin Keung $\mathrm{Lai}^{2,4}$ \\ ${ }^{1}$ School of Management, University of Science and Technology of China, Hefei 230026, China \\ ${ }^{2}$ Department of Management Sciences, City University of Hong Kong, Kowloon, Hong Kong \\ ${ }^{3}$ School of Business, Tung Wah College, Kowloon, Hong Kong \\ ${ }^{4}$ International Business School, Shanxi Normal University, Xian 710119, China
}

Correspondence should be addressed to Kin Keung Lai; mskklai@cityu.edu.hk

Received 28 December 2014; Accepted 6 March 2015

Academic Editor: Ricardo López-Ruiz

Copyright (C) 2015 Yelin Fu et al. This is an open access article distributed under the Creative Commons Attribution License, which permits unrestricted use, distribution, and reproduction in any medium, provided the original work is properly cited.

This paper develops a Shannon Entropy approach based only on the number of papers published to propose scientific institution rankings. A simple and efficient approach with weight restrictions is employed to derive the score under specific preferences. The importance degrees for each preference are determined using the concept of Shannon Entropy. Finally, a weighted linear combination of different lexicographic preferences with subjective perceptions between the corrected count and the number of articles criteria is proposed. An application to Asia-Pacific ranking of the Nature Publishing Index is to illustrate the effectiveness of our proposed method.

\section{Introduction}

Studies that evaluate and rank the scientific institutions and countries are prevalent nowadays. The Nature Publishing Index (NPI), released by Nature Publishing Group (NPG) annually, ranks scientific institutions based only upon the number of primary research articles published in Nature and its family of Nature-branded sister journals. These high quality journals are world-renowned as the preeminent platform and also serve as the benchmark for research success and achievement. Two criteria, namely, the corrected count and the number of articles, are evaluated to constitute the NPI.

The corrected count is a score taking into account the number of affiliated scientific institutions per author and the percentage of authors per institution, which definitely is a decimal fraction with a maximum of one calculated for each paper for a given institution or for a given institution or country affiliated with the paper. All authors are deemed to contribute equally to the article, and an author with multiple affiliations is assumed to contribute equally to each affiliation.

The number of articles reflects the total number of articles with which a typical institution or country is affiliated according to the presented affiliations of authors in each publication. Institutions or countries are only counted once for a particular article. The rule governing the number of articles is that the advance online papers are not counted until the issue and page numbers have been assigned.

The quasi-official ranking published by NPG relies only on the lexicographic preference of corrected count. However, this is not to say that the number of articles is free from contention. Each institution or country will highlight what suits itself best. One particular institution or country may depend heavily on the corrected count, and another may prefer article counting. Therefore, the inconsistence of these two criteria to perceptions and other associated bias inevitably reduce the utilization and acceptance of the NPI.

In this paper, we are engaged in the tremendous surge in the interest in literature and stakeholders who have not been convinced about the existing approaches to develop better-accepted approaches to rank scientific institutions. An alternative approach based on the concept of Shannon Entropy is introduced to modify the quasi-official ranking of scientific institutions of the NPI. The conventional wisdom usually derives scores by assigning weights for each criterion, respectively. However, the proposed approach improves the original ranking by proposing a weighted linear combination of different lexicographic preferences with subjective perceptions between the corrected count and the number of articles 
criteria. The inconsistent preferences between the aforementioned two criteria are not uncommon in practice. More specifically, the quasi-official ranking released by NPG prefers the corrected count to the number of articles. However, on the other hand, the traditional method relies heavily on paper counting [1]. Because it considers both the corrected count and the number of articles, the proposed approach based upon Shannon Entropy improves the quasi-official ranking presented by NPG and is better than the original method at discerning the importance degree of each preference. The most similar idea to our paper is the "h-index" presented by Hirsch [2], which depends on both the number of a scientist's publications and their impact on his or her peers, and is recommended to inform research funding and tenure decisions [3].

The rest of this paper proceeds as follows. The proposed ranking method is introduced in Section 2. The application of our ranking method to Asia-Pacific ranking of the NPI is demonstrated in Section 3. Concluding remarks are presented in Section 4.

\section{The Proposed Ranking Method}

In this section, we first investigate the solution scheme with particular lexicographic preferences between the corrected count and the number of articles criteria and then propose a weighted linear combination of different lexicographic preferences based upon the concept of Shannon Entropy, the weights of which can be represented by relative importance degrees of the preferences.

2.1. Solution Scheme. For the multiple criteria decision making problem, $\mathrm{Ng}[4,5]$ improves the work of Pearman [6] by defining a nonnegative weight $w_{i j}$ for the decision making unit (DMU) $i$ under criterion $j$ (hereafter called the $\mathrm{Ng}$ model). Mild weight restriction to reflect the ranking of the importance of the criteria to the decision maker has been assumed to derive the scores for any DMU $i$; that is, $w_{i 1} \geq$ $w_{i 2} \geq \cdots \geq w_{i J}$. The score of DMU $i$ is denoted by a weighted sum of performance measures under multiple criteria. Let $y_{i j}$ be the performance of DMU $i$ in terms of criterion $j$, which are transformed to 0-1 scale for comparable purpose,

$$
\frac{y_{i j}}{\sum_{i=1}^{I} y_{i j}}
$$

Therefore, the $\mathrm{Ng}$ model for aggregation purpose is presented as

$$
\begin{array}{ll}
\max & S_{i}=\sum_{j=1}^{J} w_{i j} y_{i j} \\
\text { s.t. } & \sum_{j=1}^{J} w_{i j}=1 \\
& w_{i j} \geq w_{i(j+1)} \geq 0, \quad j=1,2, \ldots, J-1 \\
& w_{i j} \geq 0, \quad j=1,2, \ldots, J .
\end{array}
$$

By employing the following transformations, namely, $u_{i j}=$ $w_{i j}-w_{i(j+1)}, \quad u_{i J}=w_{i J}$, and $x_{i j}=\sum_{k=1}^{j} y_{i k}$, the above model (2) is converted to the following formulations for each DMU $i$ :

$$
\begin{array}{ll}
\max & S_{i}=\sum_{j=1}^{J} u_{i j} x_{i j} \\
\text { s.t. } & \sum_{j=1}^{J} j u_{i j}=1 \\
& u_{i j} \geq 0, \quad j=1,2, \ldots, J .
\end{array}
$$

One can easily obtain the maximal score $S_{i}$ by the dual of (3), which is

$$
\begin{gathered}
\min z_{i} \\
z_{i} \geq \frac{1}{j} x_{i j}, \quad j=1,2, \ldots, J .
\end{gathered}
$$

Finally, the maximal score $S_{i}$ can be derived as $\max _{j=1,2, \ldots, j}\left\{(1 / j) \sum_{k=1}^{j} y_{i k}\right\}$.

Therefore, an integrated scoring scheme based upon the aforementioned $\mathrm{Ng}$ model can be employed to derive scores for each of the preferences, namely, the correct count $>$ the number of articles (hereafter called as P1) and the number of articles $>$ the correct count (hereafter called as P2).

2.2. A Shannon Entropy Approach. Shannon Entropy [7] plays a fundamental role in information theory, which is also a useful and effective mathematical tool to measure uncertainty. Employing Shannon Entropy as a coefficient of importance degree is pioneered by Zeleny [8] in multiple criteria decision making. The present section aims at providing a Shannon Entropy approach to evaluate the importance degree of each preference and then combine the results derived from the above two lexicographic preferences. Common weights represented by the importance degrees are determined for each of the preferences, respectively.

The motivations for using Shannon Entropy to modify the quasi-official ranking provided by NPG are summarized in the following three aspects.

(1) The discriminatory powers of the above two preferences are different, and it is difficult for us to determine a widely accepted ranking.

(2) Each of the aforementioned preferences evaluates the DMUs from a different perspective and definitely has some valuable advantages which we could not ignore.

(3) Any single preference has limited discriminatory power in evaluating and ranking; therefore, it is suitable to integrate different preferences into evaluation simultaneously.

We firstly summarize the results obtained from the different preferences for the scientific institution in the following matrix, where the first column represents the scores obtained 
TABLE 1: Result comparisons.

\begin{tabular}{|c|c|c|c|c|c|c|c|c|}
\hline \multirow{2}{*}{ Rank } & \multirow{2}{*}{ Institutions } & \multirow{2}{*}{ Corrected count } & \multirow{2}{*}{ Articles } & \multicolumn{2}{|c|}{ Ng model } & \multirow{2}{*}{ Our results } & \multirow{2}{*}{ New rank } & \multirow{2}{*}{ Rank difference } \\
\hline & & & & $\mathrm{P} 1$ & $\mathrm{P} 2$ & & & \\
\hline 1 & CAS, China & 69.44 & 212 & 0.1114 & 0.1060 & 0.1082 & 1 & $\mathbf{0}$ \\
\hline 2 & $\begin{array}{l}\text { The University of Tokyo, } \\
\text { Japan }\end{array}$ & 48.58 & 128 & 0.0779 & 0.0694 & 0.0728 & 2 & $\mathbf{0}$ \\
\hline 3 & RIKEN, Japan & 30.77 & 102 & 0.0493 & 0.0489 & 0.0491 & 3 & $\mathbf{0}$ \\
\hline 4 & Kyoto U, Japan & 26.35 & 69 & 0.0423 & 0.0375 & 0.0394 & 5 & -1 \\
\hline 5 & NUS, Singapore & 22.07 & 87 & 0.0384 & 0.0413 & 0.0401 & 4 & +1 \\
\hline 6 & UQ, Australia & 19.83 & 69 & 0.0323 & 0.0328 & 0.0326 & 8 & -2 \\
\hline 7 & Osaka U, Japan & 19.74 & 62 & 0.0317 & 0.0306 & 0.0310 & 10 & -3 \\
\hline 8 & PKU, China & 19.66 & 79 & 0.0345 & 0.0375 & 0.0363 & 6 & +2 \\
\hline 9 & SNU, South Korea & 17.47 & 51 & 0.0280 & 0.0261 & 0.0269 & 11 & -2 \\
\hline 10 & Tsinghua U, China & 17.05 & 68 & 0.0298 & 0.0323 & 0.0313 & 9 & +1 \\
\hline 11 & NTU, Singapore & 15.07 & 41 & 0.0242 & 0.0218 & 0.0228 & 13 & -2 \\
\hline 12 & $\begin{array}{l}\text { The University of } \\
\text { Melbourne, Australia }\end{array}$ & 13.83 & 80 & 0.0301 & 0.0380 & 0.0348 & 7 & +5 \\
\hline 13 & USTC, China & 13.49 & 39 & 0.0216 & 0.0201 & 0.0207 & 16 & -3 \\
\hline 14 & Nanjing U, China & 12.93 & 33 & 0.0207 & 0.0182 & 0.0192 & 19 & -5 \\
\hline 15 & SJTU, China & 12.46 & 40 & 0.0200 & 0.0195 & 0.0197 & 18 & -3 \\
\hline 16 & Fudan U, China & 11.85 & 50 & 0.0214 & 0.0238 & 0.0228 & 12 & +4 \\
\hline 17 & Tohoku U, Japan & 11.61 & 44 & 0.0198 & 0.0209 & 0.0204 & 17 & 0 \\
\hline 18 & ANU, Australia & 11.24 & 39 & 0.0183 & 0.0185 & 0.0184 & 20 & -2 \\
\hline 19 & Monash U, Australia & 11.09 & 50 & 0.0208 & 0.0238 & 0.0226 & 14 & +5 \\
\hline 20 & $\begin{array}{l}\text { Tokyo Institute of } \\
\text { Technology, Japan }\end{array}$ & 10.54 & 28 & 0.0169 & 0.0151 & 0.0158 & 26 & -6 \\
\hline 21 & Nagoya U, Japan & 10.52 & 31 & 0.0169 & 0.0158 & 0.0162 & 23 & -2 \\
\hline 22 & KAIST, South Korea & 10.49 & 34 & 0.0168 & 0.0165 & 0.0166 & 22 & $\mathbf{0}$ \\
\hline 23 & ZJU, China & 10.05 & 37 & 0.0168 & 0.0176 & 0.0173 & 21 & +2 \\
\hline 24 & $\mathrm{~A} * \mathrm{STAR}$, Singapore & 10.04 & 48 & 0.0195 & 0.0228 & 0.0215 & 15 & +9 \\
\hline 25 & POSTECH, South Korea & 9.04 & 26 & 0.0145 & 0.0134 & 0.0139 & 30 & -5 \\
\hline 26 & Kyushu U, Japan & 8.72 & 30 & 0.0141 & 0.0143 & 0.0142 & 29 & -3 \\
\hline 27 & $\begin{array}{l}\text { The University of Sydney, } \\
\text { Australia }\end{array}$ & 8.63 & 35 & 0.0152 & 0.0166 & 0.0161 & 25 & +2 \\
\hline 28 & BGI, China & 8.6 & 33 & 0.0147 & 0.0157 & 0.0153 & 27 & +1 \\
\hline 29 & NTU, Taiwan & 8.59 & 25 & 0.0138 & 0.0128 & 0.0132 & 31 & -2 \\
\hline 30 & HKUST, China & 7.95 & 12 & 0.0128 & 0.0092 & 0.0106 & 38 & -8 \\
\hline 31 & NIMS, Japan & 7.71 & 28 & 0.0128 & 0.0133 & 0.0131 & 32 & -1 \\
\hline 32 & NTT Group, Japan & 7.17 & 11 & 0.0115 & 0.0084 & 0.0096 & 41 & -9 \\
\hline 33 & Keio U, Japan & 6.92 & 22 & 0.0111 & 0.0108 & 0.0109 & 37 & -4 \\
\hline 34 & UNSW, Australia & 6.69 & 37 & 0.0142 & 0.0176 & 0.0162 & 24 & +10 \\
\hline 35 & CSIRO, Australia & 6.58 & 34 & 0.0134 & 0.0162 & 0.0150 & 28 & +7 \\
\hline 36 & AIST, Japan & 6.57 & 21 & 0.0105 & 0.0103 & 0.0104 & 39 & -3 \\
\hline 37 & CAMS \& PUMC, China & 6.21 & 28 & 0.0116 & 0.0133 & 0.0126 & 33 & +4 \\
\hline 38 & IISC, India & 6.12 & 11 & 0.0098 & 0.0075 & 0.0084 & 47 & -9 \\
\hline 39 & Hokkaido U, Japan & 6.1 & 18 & 0.0098 & 0.0092 & 0.0094 & 44 & -5 \\
\hline 40 & Academia Sinica, Taiwan & 5.8 & 26 & 0.0108 & 0.0124 & 0.0117 & 34 & +6 \\
\hline 41 & $\begin{array}{l}\text { University of Tsukuba, } \\
\text { Japan }\end{array}$ & 5.77 & 15 & 0.0093 & 0.0082 & 0.0086 & 45 & -4 \\
\hline 42 & Yonsei U, South Korea & 5.71 & 26 & 0.0108 & 0.0124 & 0.0117 & 35 & 7 \\
\hline
\end{tabular}


TABle 1: Continued.

\begin{tabular}{|c|c|c|c|c|c|c|c|c|}
\hline \multirow{2}{*}{ Rank } & \multirow{2}{*}{ Institutions } & \multirow{2}{*}{ Corrected count } & \multirow{2}{*}{ Articles } & \multicolumn{2}{|c|}{ Ng model } & \multirow{2}{*}{ Our results } & \multirow{2}{*}{ New rank } & \multirow{2}{*}{ Rank difference } \\
\hline & & & & $\mathrm{P} 1$ & $\mathrm{P} 2$ & & & \\
\hline 43 & Jilin U, China & 5.44 & 16 & 0.0087 & 0.0082 & 0.0084 & 48 & -5 \\
\hline 44 & NINS, Japan & 5.27 & 18 & 0.0085 & 0.0086 & 0.0085 & 46 & -2 \\
\hline 45 & Sun Yat-sen U, China & 4.98 & 25 & 0.0099 & 0.0119 & 0.0111 & 37 & +8 \\
\hline 46 & SKKU, South Korea & 4.68 & 23 & 0.0092 & 0.0109 & 0.0102 & 40 & +6 \\
\hline 47 & Macquarie U, Australia & 4.56 & 21 & 0.0086 & 0.0100 & 0.0094 & 42 & +5 \\
\hline 48 & JAMSTEC, Japan & 4.52 & 14 & 0.0072 & 0.0069 & 0.0071 & 49 & -1 \\
\hline 49 & Sichuan U, China & 4.52 & 21 & 0.0086 & 0.0100 & 0.0094 & 43 & +6 \\
\hline 50 & $\begin{array}{l}\text { Huazhong Agricultural U, } \\
\text { China }\end{array}$ & 4.5 & 8 & 0.0072 & 0.0055 & 0.0062 & 50 & $\mathbf{0}$ \\
\hline
\end{tabular}

from $\mathrm{P} 1$ and the second column shows the results from P2; the scores are derived by the presented $\mathrm{Ng}$ model in Section 2.1:

$$
S_{I \times 2}=\left(\begin{array}{cc}
S_{11} & S_{12} \\
S_{21} & S_{22} \\
\vdots & \vdots \\
S_{I 1} & S_{I 2}
\end{array}\right)
$$

Note that the results derived from the $\mathrm{Ng}$ model are 0 - 1 scale. Therefore, for the purpose of comparing, the second column in matrix (5), namely, $S_{12}, S_{22}, \ldots, S_{I 2}$, is transformed data according to (1).

In line with the work of Soleimani-Damaneh and Zarepisheh [9], we introduce the following five steps to determine the respective weights for both preferences $\mathrm{P} 1$ and P2 on the basis of Shannon Entropy.

Step 1. Normalize the matrix $S_{I \times 2}$ by $s_{i j}=S_{i j} / \sum_{i=1}^{I} S_{i j}$.

Step 2. Determine the entropy for each ranking; $f_{j}=$ $-[\ln (n)]^{-1} \sum_{i=1}^{I} s_{i j} \ln \left(s_{i j}\right)$.

Step 3. Calculate the degree of discriminability for each ranking as $d_{j}=1-f_{j}$.

Step 4. Compute the weight $\lambda_{j}$ for the ranking system $j, j=$ 1,2 by normalizing $d_{j}$; that is, $\lambda_{j}=d_{j} / \sum_{j=1}^{2} d_{j}$.

Step 5. Calculate the overall scores for DMU $i ; S_{i}=$ $\sum_{j=1}^{2} \lambda_{j} S_{i j}, i=1,2, \ldots, I$.

\section{Numerical Illustrations}

For the purpose of demonstrating the usefulness of our proposed approach, we apply it to the Asia-Pacific ranking of the NPI released by NPG on 2014-10-20 listed in Table 1. The current index date range is from 2013-10-21 to 2014-1020. These rankings only include articles published as research papers (articles, letters, and brief communications) or reviews in Nature and/or Nature monthly research journals.

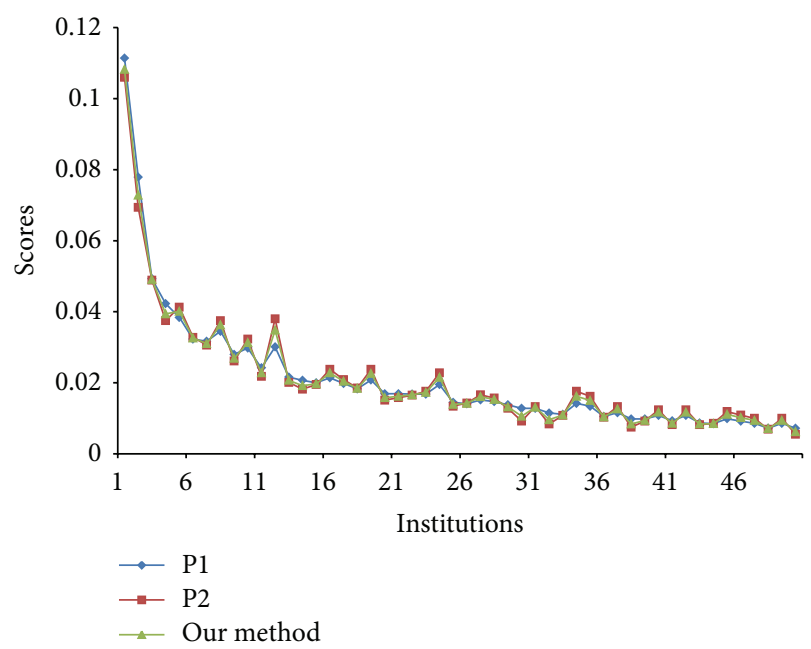

Figure 1: Comparisons among P1, P2, and our method.

We directly apply the $\mathrm{Ng}$ model to derive relative scores for both $\mathrm{P} 1$ and $\mathrm{P} 2$ and then calculate the final results according to our proposed method based upon Shannon Entropy, where the common weights for P1 and P2 are $\lambda_{1}=$ 0.4018 and $\lambda_{2}=0.5982$, respectively. Related results and some comparisons have been summarized in Table 1.

Compared with the quasi-official ranking released by NPG, 44 out of the 50 institutions are ranked differently. More specifically, 18 institutions are up-ranked while 26 institutions are down-ranked.

Figure 1 vividly compares the results among P1, P2, and our method, where we denote the institutions by the ranking position published by NPG.

\section{Conclusions}

In this paper, a Shannon Entropy approach based only upon the number of articles published by institutions has been developed to modify the quasi-official ranking released by NPG, which may face some problem to determine a widely accepted ranking for different preferences. This paper presents a model, which effectively determines the 
importance degree of two different preferences between the corrected count and the number of articles. The common weights are determined for these two preferences, respectively. The scores derived from the proposed method are calculated to provide a unique sequence of the institutions. The ranking method presented in this paper is originated from easily understood premises and provides interesting insights for ranking construction to avoid controversy. The results of numerical practice illustrate different perspective and discriminatory power of different preferences. In future, the method presented in this paper could be applied to other multiple criteria decision making problems, which should contain more than only two preferences discussed here. For more complex ranking and performance measurement problem, this method can also extend and exploit its discriminatory power.

\section{Conflict of Interests}

The authors declare that there is no conflict of interests regarding the publication of this paper.

\section{References}

[1] J.-F. Molinari and A. Molinari, "A new methodology for ranking scientific institutions," Scientometrics, vol. 75, no. 1, pp. 163-174, 2008.

[2] J. E. Hirsch, "An index to quantify an individual's scientific research output," Proceedings of the National Academy of Sciences of the United States of America, vol. 102, no. 46, pp. 1656916572, 2005.

[3] P. Ball, "Index aims for fair ranking of scientists," Nature, vol. 436, article 900, 2005.

[4] W. L. Ng, "A simple classifier for multiple criteria ABC analysis," European Journal of Operational Research, vol. 177, no. 1, pp. 344-353, 2007.

[5] W. L. Ng, "An efficient and simple model for multiple criteria supplier selection problem," European Journal of Operational Research, vol. 186, no. 3, pp. 1059-1067, 2008.

[6] A. D. Pearman, "A weighted maximin and maximax approach to multiple criteria decision making," Operational Research Quarterly, vol. 28, no. 3, part 1, pp. 584-587, 1977.

[7] C. E. Shannon, "A mathematical theory of communication," Bell System Technical Journal, vol. 27, no. 4, pp. 623-656, 1948.

[8] M. Zeleny, Multiple Criteria Decision Making, McGraw-Hill, New York, NY, USA, 1982.

[9] M. Soleimani-damaneh and M. Zarepisheh, "Shannon's entropy for combining the efficiency results of different DEA models: method and application," Expert Systems with Applications, vol. 36, no. 3, part 1, pp. 5146-5150, 2009. 


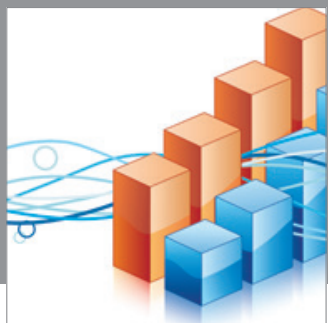

Advances in

Operations Research

mansans

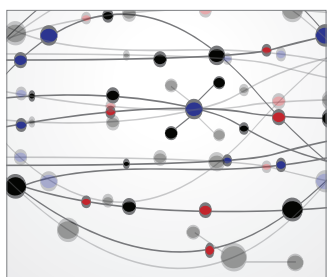

The Scientific World Journal
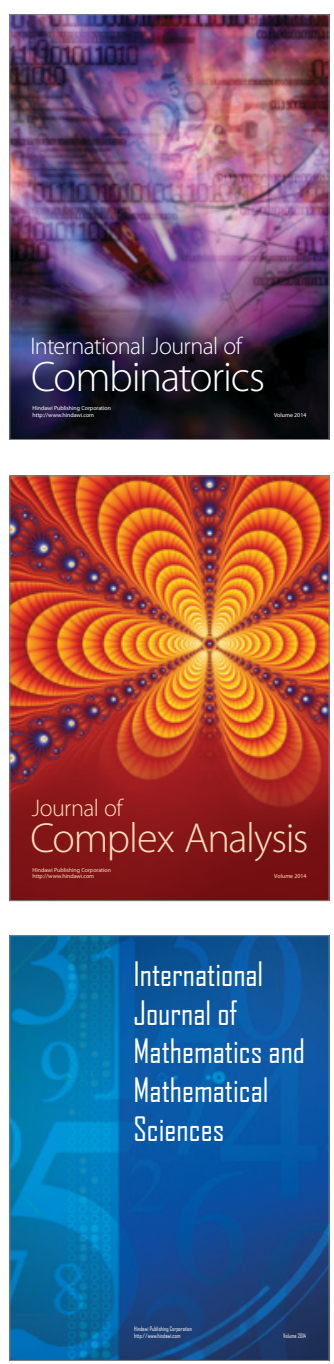
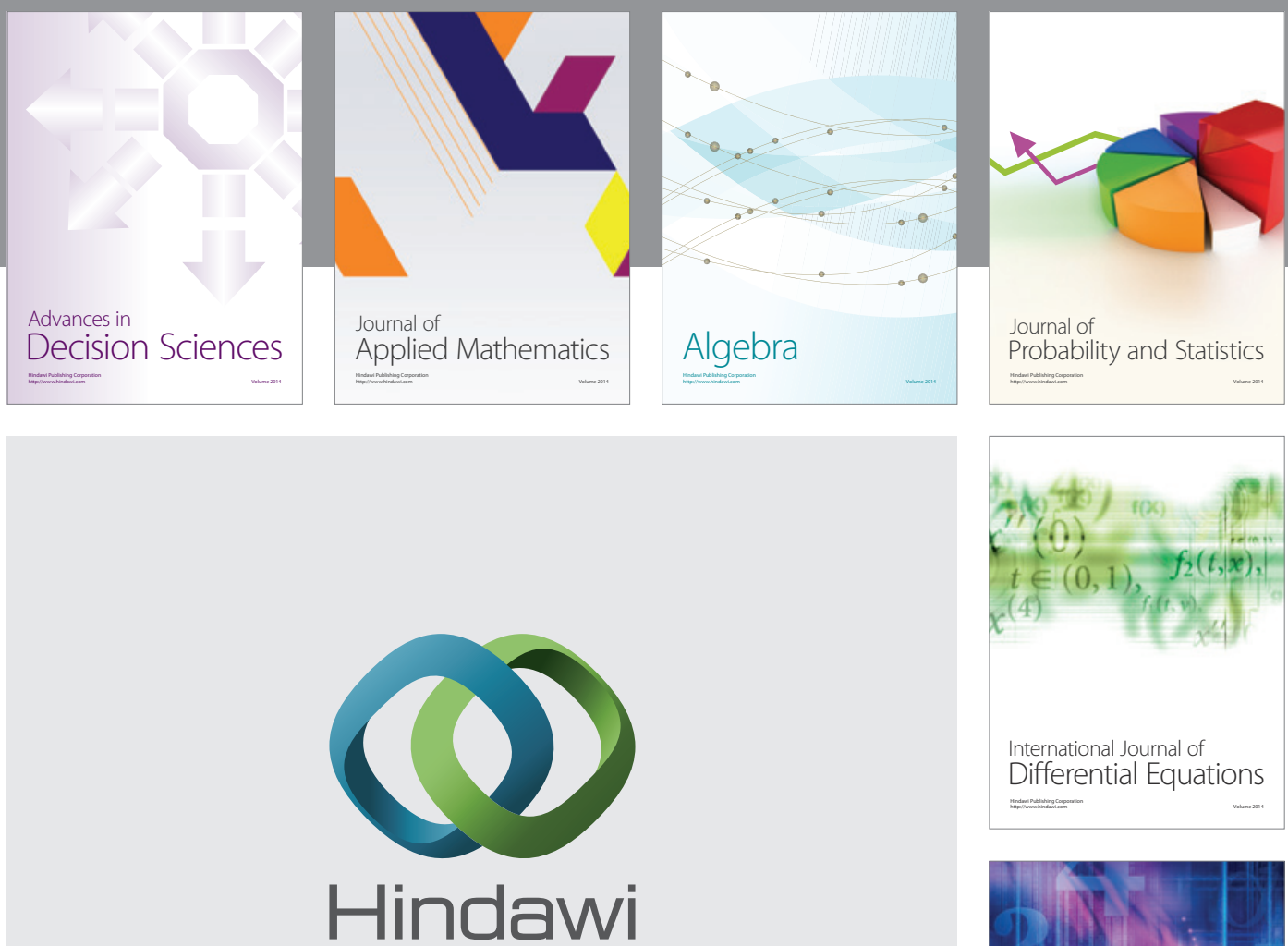

Submit your manuscripts at http://www.hindawi.com
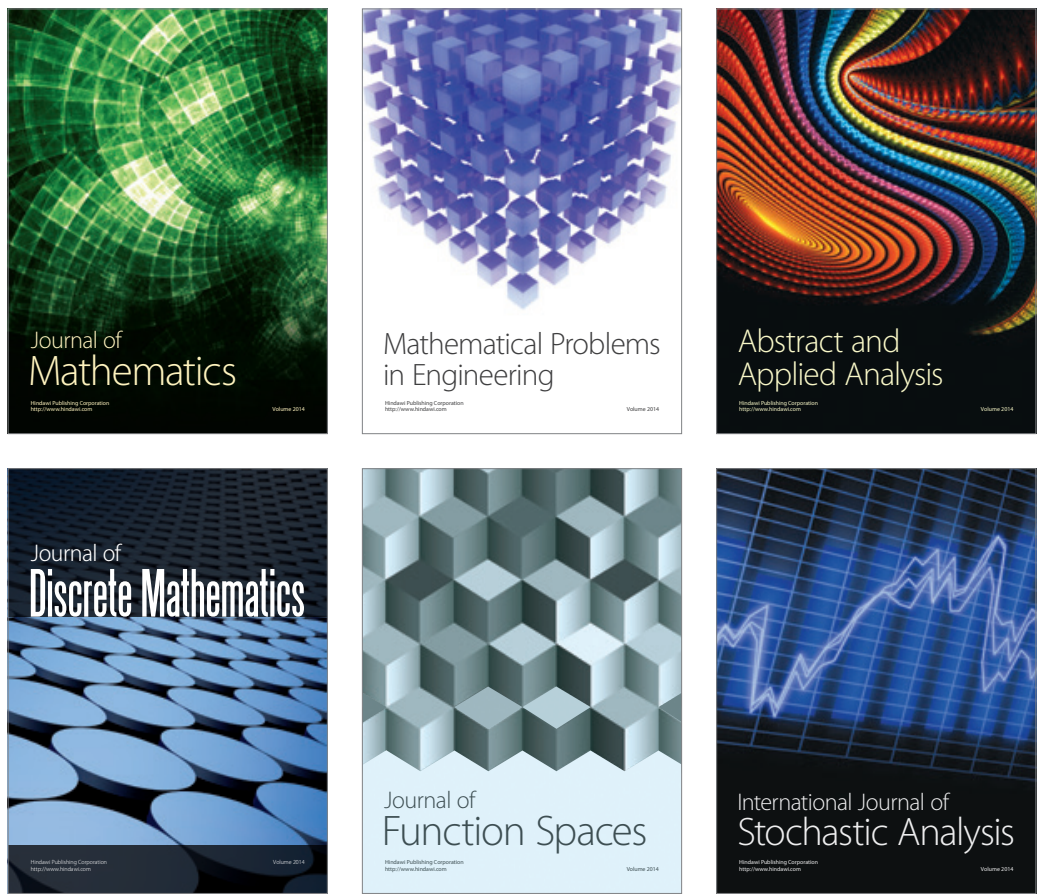

Journal of

Function Spaces

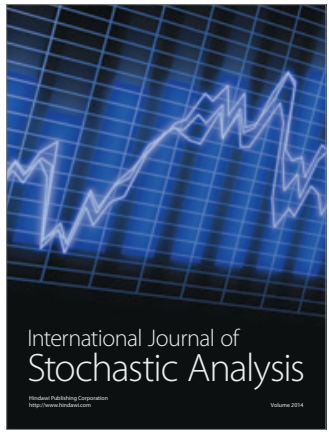

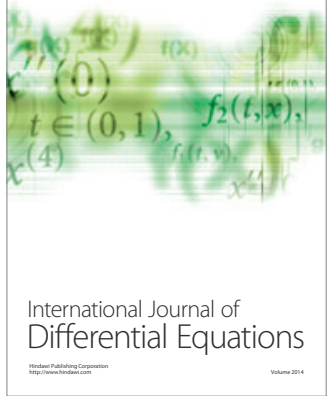
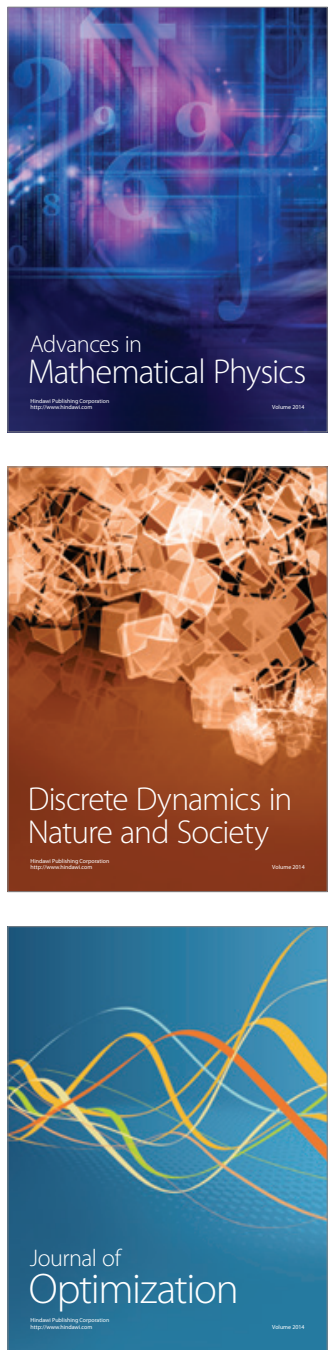